\title{
Creating new business models around a world-class library patron experience
}

\author{
Mitchell Davis \\ Chief Business Officer, BiblioLabs, 100 Calhoun Street, Suite 220, Charleston, SC 29401, USA
}

\section{Introduction}

When my co-founders and I began BookSurge in 2000, it was an excellent time to dive into the publishing world, especially if you knew nothing about it. We had no previous publishing industry experience that would inform our view of how the company would operate. In this mindset, we asked ourselves: Why not be a publisher, printer, and retailer all at once? The slate was totally clean. I view BiblioBoard and the way we see the library market in a similar way. We survey the landscape of the library world primarily as technologists rather than as people who have to support legacy business models when building tools for libraries.

Over recent years, there has been a great deal of chatter surrounding the future of libraries and publishing. The predominant arguments range from the pessimistic "Libraries are becoming obsolete! No one reads real books anymore!" to radical traditionalists who refuse to buy a Kindle or acknowledge the growth of e-material. While the truth lies somewhere in the middle, the more important argument is about the mindset of librarians, patrons and the general public.

How are libraries competing with the elegant user experiences delivered by consumer companies such as Amazon, Netflix, Evernote and other mobile experiences that have set a very high bar for user expectations?

\section{Current library landscape}

Currently, the library content landscape interacts with users while relying on a disjointed interface and asynchronous lending models. A mash-up of one-book/one-user, short-term loan, patron-driven and demand-driven acquisitions systems all built into a library website with different access portals cannot compare to the simplicity of Amazon's OneClick ${ }^{\mathrm{TM}}$ ordering system. Consumer behavior is changing the way people view the world. Can you imagine going to Netflix and being told that you couldn't watch a movie because someone else was watching it? Neither can most people and they cannot compartmentalize the library in their view of the media world. They simply don't engage with things that are frustrating or hard.

Right now, the digital user experience in the library world frustrates people into the arms of retailers. According to recent studies the library eBook user-experience has about a tenth of the market penetration 
as consumer eBooks and an alarming $80 \%$ attrition rate, meaning most people who have an eBook lending account with their library do not use it.

The timelier problem that libraries should focus on is learning to compete for patron attention and time in the fast-paced digital world. In this day and age, libraries are in the business of competing with big business and must learn to encourage success. Present eBook business models in the library world are built on an artificial scarcity that places the library in a no-win situation. Today, public libraries spend lots of money to deliver a sub-standard eBook experience. No matter how many copies of a single-user bestselling eBook they buy (typically marked up from the list price), they cannot make it comprehensively available to their entire patron base or come close to meeting the community's peak demand.

This approach may drive library usage in a raw sense, but in a world of finite resources, it seems shortsighted. Perpetuating a less-than-satisfactory eBook experience creates a situation where a small base of power users drive usage on a small number of expensive eBooks, while millions of eBooks become inaccessible through the library at all because of the exhausted acquisitions budget. When demand for a former bestseller lessens, the library has an excessive amount of digital copies lying around that it cannot sell or give away.

Consider the marketing that is done by successful companies such as Amazon. When I worked at Amazon, the marketing tactic was simple: free shipping. They understood it is impossible to successfully market a bad user experience. The modern world values two types of marketing: word-of-mouth marketing and user experience. Libraries have neither on their side.

We should ask ourselves: Why hasn't the shift to provide a better library patron experience happened yet?

Libraries are dependent on vendors for content and the systems they use to deliver that content. The vendors who serve them can suffer from a classic case of the "Innovator's Dilemma". This idea, originally purported by Clayton Christensen, suggests that some companies may place too much emphasis on customer's current needs and do not address potential or unstated needs that will arise in the future. These companies, which often times fall behind, are simply following the money rather than thinking ahead of the curve.

To create successful business models and provide a better experience, librarians will have to employ a different sense of urgency when considering the future of this great public institution. The success of the company, or the library, becomes contingent on the chemistry of the people who work for the library and for the vendors that they select. How prepared are those vendors to continue adapting quickly into the future? Those who wish to make a difference in the library world must consider the library's competition, brilliant user experiences from big companies, and focus on ways to bring the library up to that speed.

\section{A new business model - BiblioBoard}

This is not just a question of costs, which has typically been the reason libraries say that they cannot compete with these experiences. New vendors like BiblioLabs have created affordable platforms to help the libraries adapt to this new reality. We have a super-motivated and smart group of people who have built just such a system with BiblioBoard and I am happy to be able to share with you guys just a few of the things we are working on currently.

BiblioBoard Library is the PatronsFirst ${ }^{\mathrm{TM}}$ mobile library geared towards helping libraries solve issues of content integration and presentation. By offering a unified, world-class user experience and providing 
multi-media content on an unlimited, multi-user basis, BiblioBoard eliminates the complexity often associated with navigating the numerous information silos within a library. It combines a simple curation tool, BiblioBoard Creator and an unbeatable patron experience that is not limited to the web and, in fact, stretches across all devices. As more and more users move to devices and tablets, libraries must be able to meet the need to reach their patrons on all platforms, so no one is left behind.

BiblioBoard's customers have adopted the technology to suit the needs of their institution. Partners range from large national libraries such as the British Library, who sought to organize primary source materials, to individual artists looking for a channel to promote and house digital copies of their works. Libraries across the world have implemented the use of Creator and Library in their institutions to provide a quality patron experience to users of their digital resources.

I will briefly describe a few of the use cases seen on BiblioBoard over the past year, but in order to understand the nuances of the varying academic, school and personal uses of BiblioBoard Library and Creator, please use the following log-in to access a NFAIS demo of BiblioBoard Library at: https://library.biblioboard.com (User name: nfais@biblioboard.com; Password: nfais2014).

\section{BiblioBoard case studies}

All are available at: http://www.biblioboard.com/archives.html.

\section{British Library: 19th-century historical books}

The British Library is a National Library with over 80,000 digitized books from the 19th century in their vast collections. The App built for them by BiblioLabs in 2011 was downloaded more than 250,000 times in the first two weeks and was used by individuals in over 160 countries. The project was a huge success, but presented challenges in updating the user experience as technology moved forward. The work was also not scalable to other institutions.

The British Library sought a way to provide more granular context for patrons on a large corpus of digitized primary source materials. They wanted to provide global access to their 19th-century collection in a way that was scalable for the curators and the public. Focus then shifted to making that success sustainable by creating smaller thematic collections using BiblioBoard ${ }^{\circledR}$ Creator. A part-time curator was able to create over a dozen Anthologies in less than three months and the library spent nothing on marketing, development or programming. These Anthologies (plus many more) are now available globally on tablet devices via native Applications and on the web with no ongoing costs to the library.

In addition to creating an elegant experience interacting with these valuable historical materials, the British Library has also created a cost-recovery revenue stream by making their BiblioBoard collections available for sale into libraries and schools.

\section{Wake Forest University: Coming home to mother dear}

Wake Forest University's Z. Smith Reynolds Library houses vast historical collections in their Archives, and researchers routinely make use of these on-campus resources by taking a first-hand look at the rare and semi-precious materials. With Homecoming approaching, the library needed to create an 
online resource to be shared with visiting alumni groups, both in-person and online, at a variety of onand off-campus reunion events.

Librarians chose relevant (but fun) homecoming-related archival materials such as football programs, fight song recordings, yearbooks, and other newly-digitized materials, dating back as far as the 1930s. Using BiblioBoard ${ }^{\circledR}$ Creator, these resources were quickly rendered into one portable anthology, which is easily and freely shared among Wake Forest family, friends and alumni via laptops and tablets.

\section{David Ensminger: The Punk and Indie Rock Compendium}

David Ensminger is a professor and author published by University of Texas Press, University Press of Mississippi and PM Press. He was able to create an engaging Punk and Indie Compendium, a vivid survey of multimedia material from the underground music scene spanning the 1980-2000s, including video, photography and music. BiblioBoard ${ }^{\circledR}$ Creator is a powerful tool that blurs the line between academic, popular and archival publishing and a perfect match for an individual archivist with these type materials. With this type of tool, we see a new type of self-publishing where individual subject matter experts can publish multi-media databases about a niche subject that can be made available globally.

Standard books did not provide the right container, hands-on involvement and archival breadth for the kind of storytelling in which he wished to engage. BiblioBoard Creator ensured a vibrant, high-quality and modern interface on the $\mathrm{iPad}^{\circledR}$.

\section{Australian Historic Shipwreck Project}

The goal of the Australian Historic Shipwreck Preservation Project (AHSPP) was to research and develop protocols for the rapid excavation, detailed recording and subsequent in-situ preservation of significant shipwrecks off the Australian coast. AHSPP showcased collaborative archaeological work that shed new light on history and contributed to the furtherance of the field of study. However, the folks behind the project sometimes found it difficult to relay their scholarly research to a wider public audience.

With BiblioBoard, AHSPP's manager was able to put together an anthology titled Preserving the Colonial Trader Clarence in time to display at a national conference in front of a jury of her peers. Featuring high-resolution images, short videos, interviews and more, the anthology is also easily-accessible by anyone interested in maritime archaeology, heritage and preservation.

\section{Clayborne Carson}

Dr. Clayborne Carson has dedicated much of his life to realizing the ideals of the late Dr. Martin Luther King, Jr. Much of Carson's research was gathered first-hand as a result of his participation in the freedom struggles grassroots efforts in the 1960s. His subsequent scholarship culminated in his being handpicked by Coretta Scott King to edit and publish her husband's papers and, later, in his founding of the Martin Luther King, Jr. Research and Education Institute at Stanford University. He has also published more than a dozen books and collected a treasure trove of artifacts from the civil rights movement. Using BiblioBoard Creator, he was able to publish his private archives so that they could be shared with researchers and institutions around the world. 


\title{
10. Benjamin Timpson
}

Benjamin Timpson is an MFA student at the University of Indiana and a popular contemporary artist. Although he is a classically-trained painter, Timpson made a splash by creating art from found objects, such as flower petals, bug legs and human hair. His artwork, first created on tiny glass slides and then blown up onto canvasses, is hard to portray in mere imagery alone. Timpson wanted to provide insight into his process as well as make his work discoverable to a larger audience.

Using BiblioBoard ${ }^{\circledR}$ Creator, Timpson collected videos, images and articles depicting his unique creative process and organized them into a dark and hauntingly beautiful Anthology. Timpson is working with his professors to make sure at that his Anthology is cataloged by the library and that all of his art is available for the future. Timpson has been in conversation with the school to develop programs to work with other students in a similar way. This approach, besides providing a huge value to the student in letting them develop interactive portfolios as part of their projects, also catalogs the entire creative output of the students on campus seeking MFA degrees. ${ }^{1}$

\begin{abstract}
About the author
Mitchell Davis is a publishing and media entrepreneur. He was the founder in 2000 of BookSurge (acquired in 2005 and now Amazon's CreateSpace), the world's first integrated global print-on-demand and publishing services company. After working in senior management at Amazon for two years, he co-founded BiblioLabs in 2007, where he serves as Chief Business Officer. BiblioLabs are the creators of BiblioBoard: an award-winning mobile App and web platform that is reinventing the modern librarypatron user experience. In a little over a year, BiblioBoard has signed on over 400 publishers $(100,000+$ eBooks) and over 2,500 libraries.
\end{abstract}

\footnotetext{
${ }^{1}$ This paper is based upon a presentation given at the 2014 NFAIS Annual Conference in Philadelphia, PA, USA on February 25, 2014. The slides can be accessed on the NFAIS Web site at http://www.nfais.org.
} 